\title{
Essay
}

\section{Using Critical Literacy to Explore Genetics and its Ethical, Legal, and Social Issues with In-Service Secondary Teachers}

\author{
Michael L. Gleason, ${ }^{*}$ Megan E. Melançon, ${ }^{\dagger}$ and Karynne L. M. Kleine ${ }^{\ddagger}$ \\ Departments of *Biological and Environmental Sciences, ${ }^{\dagger}$ English, Speech, and Journalism, and ${ }^{\ddagger}$ Early \\ Childhood and Middle Grades Education, Georgia College \& State University, Milledgeville, GA 31061
}

Submitted September 9, 2009; Revised May 24, 2010; Accepted June 21, 2010

Monitoring Editor: Elisa Stone

\begin{abstract}
The described interdisciplinary course helped a mixed population of in-service secondary English and biology teacher-participants increase their genetics content knowledge and awareness of Ethical, Legal, and Social Implications (ELSI) that arose from discoveries and practices associated with the Human Genome Project. This was accomplished by applying a critical literacy approach that allows people develop cognitive skills such that they are able to "read the world" (Wink, 2004). The approach is one that permits readers to go beyond the literal text to examine what is present as well as what is missing as it relates to issues of equity and fairness. Becoming critically literate enabled these teacher-participants to challenge the subtle attitudes, values, and beliefs conveyed by a range of written and oral texts. The teacher-participants in this course improved their critical literacy skills by actively reading, critically writing about, and using evidence to support their conclusions about issues arising from advances in human genetics. A biologist, a linguist, and an educator collaboratively designed and taught the course. The personalized focus on the integration of thoughtful reading and writing in this class enhanced the teacher-participants' $(n=16)$ professional and intellectual development and will potentially improve learning in their biology and English classrooms in the future.
\end{abstract}

\section{INTRODUCTION}

When we each participated in the ELSI (Ethical, Legal, and Social Implications) summer institutes at Dartmouth University we were struck by the intricate implications of the Human Genome Project (HGP) and the possibilities for creating a highly-motivating learning experience with the topic. We also realized that as different content area specialistsmolecular biology, linguistics, and teacher educator with a background in history and philosophy of science - teaching

DOI: $10.1187 /$ cbe.09-09-0065

Address correspondence to: Michael L. Gleason (mike.gleason@ gcsu.edu).

(C) 2010 M. L. Gleason et al. CBE-Life Sciences Education (C) 2010 The American Society for Cell Biology. This article is distributed by The American Society for Cell Biology under license from the author(s). It is available to the public under an AttributionNoncommercial-Share Alike 3.0 Unported Creative Commons License (http://creativecommons.org/licenses/by-nc-sa/3.0). at a public liberal arts institution the topic would lend itself to an interdisciplinary approach to which we could each contribute. So in the fall of 2005 we searched for an important developmental platform from which to stage the intended outcomes of the course. We settled upon critical literacy, the ability and stance of readers to interrogate the implicit "statements" of a text, because we believed that as teachers' critical literacy skills increased so too was the likelihood that they could positively promote the critical literacy skills of their students. Only with the citizenry's analytical skills solidly in hand can a democracy thrive. We proposed a course entitled "Critical Literacy in Genetics: Ethical and Social Implications of the Human Genome Project" to be collaboratively taught June, 2006.

\section{History and Design of the Course}

Two of us had previously applied our ELSI experiences as we taught summer/fall courses in 2002 and 2003 for secondary life science teachers, which provided some of the in- 
sights for the development of this course (Gleason and Kleine, 2003). From those classroom experiences we learned significant lessons as to how to close the gap between the broad implications heralded by cutting-edge genetics and the negligible knowledge base the average citizen, or in our case, biology teacher, had accessible for this focus. We knew that the topic was a highly-engaging one and that it could be understood from many perspectives, but after teaching two iterations to in-service science teachers we also wanted to do more to prod them to consider the worth of what they were learning. From these science courses we learned that the participants acquired important knowledge of molecular genetics (e.g., transformation and gene expression) and, to a lesser extent through the class discussion component that we incorporated, developed an appreciation for the HGP's ethical ramifications. Our evaluations also informed us that the teachers augmented their critical thinking skills, a positive result. The participants in these earlier offerings also discovered some good hands-on activities that they could apply in their life science classrooms. However, we sought some greater personal effect on teacher-participants' everyday lives than we had been able to imbue previously, a change in disposition toward the value of thinking critically as well as enhancement of their ability to apply skepticism to the act of "reading the world" (Wink, 2004).

As the three of us came together to create a course for 2006 we reflected on our own summer experiences at the ELSI Institutes. We realized that there we had been expected to reconcile the consequences of the HGP that provide advantages to individuals and society concomitantly with its disadvantages. We performed an ongoing mental calculus that was enriched by the speaking, reading, writing, viewing, and discussing that we did in community. In other words, in the ELSI workshops we built our understanding through small group work and roundtables of the whole to continually assess whether the benefits wrought by the HGP were worth the drawbacks and if so, under what circumstances. To question, to wonder, to assert, to defend, and to persuade all seemed to be powerful elements of our own learning experiences. We wanted a similarly empowering and intellectually stimulating experience for the teacher-participants we planned to teach. Thus we looked for a greater imperative for the teacher-participants to learn about the HGP than merely to pass it on to others. As we learned about critical literacy we determined that it could provide the pivot point for a course that could offer empowering and intellectual outcomes. Furthermore critical literacy aligned well with the skeptical attitude and logic skills necessary to engage in scientific thinking. Thus we concluded that an interdisciplinary course for teaching about the HGP that developed the critical literacy stance of the participants was a good meld of our aptitudes and shared goals. Moreover, our goal was not only to improve the critical literacy of our students (teacherparticipants), but also through our teacher-participants to impact the teaching and literacy levels of their middle grades and high-school English and biology students.

\section{Critical Literacy}

We took a critical literacy approach in this class. This is not a single instructional strategy as much as a means to assist readers in adopting a skeptical, analytical mindset, not un- like that used by a trained scientist in her work. Because critical literacy enables one to challenge the subtle attitudes, values, and beliefs conveyed by a range of written and oral "texts" (Alvermann and Hagood, 2000) group discussion of shared readings is the most effective way to open texts to multiple interpretations and "teach" this concept. Critical literacy has its roots in the pedagogical theories of Paulo Freire (1970) who examined how changes could be effected in the lives of the Brazilian oppressed by having them learn to read and write and then to use those literacy skills to actively question those in power. As noted by Taylor (1993), Freire argued for raising learners' consciousness through discussion and writing and felt that their learning had to come out of their lived experiences. When a critically literate person engages with a text she would be examining issues of language, power, equality, justice, and society. A critically literate teacher would go beyond these issues to reflect on his own teaching, reading, and writing. One proponent, Wink (2004), has likened critical literacy to ". . . learning to read the world". Because the HGP holds countless propositions for current and future worlds, which cannot necessarily be taken at face value, we believed that teaching the participants to be critically literate would enable them to scrutinize the implications and call them into question, understanding that no text is neutral and all knowledge is situated.

The notion of critical literacy that emerged from the work of Paolo Freire as he advocated for adult Brazilians to question the status quo ultimately concerns itself with identity formation (Freire, 1970). The term has come to have many nuances, but we were guided by a narrower one that Simpson (1996) used in teaching middle-school teachers to read and write, namely that texts reflects a particular view and as such do not necessarily correspond to "reality." Simpson also noted that authors are influential because they write in such a way so as to position the reader to respond to a text in particular ways: with the selection of the language they use, the point of view they take, and other similarly dynamic choices they make when drafting pieces. Our goal was to enable the participants to more actively question texts so that they would read and write in such a way as to reflect their understanding of this power of their growing literacy skills.

For this course we elected to expand the meaning of literacy to include both the traditional notion of reading and writing competence as well as the more current understanding of this term as applied in science (Freeman and Taylor, 2006). According to the National Science Education Standards, "scientific literacy means that a person can ask, find, or determine answers to questions derived from curiosity about everyday experiences. It entails being able to read with understanding articles about science in the popular press and to engage in social conversation about the validity of the conclusions. Scientific literacy implies that a person can identify scientific issues underlying national and local decisions and express positions that are scientifically and technologically informed. A literate citizen should be able to evaluate the quality of scientific information on the basis of its source and the methods used to generate it. Scientific literacy also implies the capacity to pose and evaluate arguments based on evidence and to apply conclusions from such arguments appropriately" (National Research Council, 1995, emphasis ours). 
In other words, to be scientifically literate carries with it several capacities-dispositional, procedural, and cognitive-that one would apply in school and beyond. What language literacy and scientific literacy have in common then is the sense that increased competence in either advances one's intellectual development and ability to carry out systematic thinking that involves abstraction. In Freire's assessment of traditional literacy instruction he recognized the liberating aspect that literacy and critical thinking, which he called "thought-language," entailed. In fact he referred to the process of teaching adults to read and write as "cultural action for freedom" and understood that the outcome of being critically literate didn't change merely one person but positively affected the entire culture (Freire, 1970). Our thought was that we could join the advancement of both scientific and language literacies together as "critical literacies" to enhance and develop the participants' knowledge, and ultimately their students' knowledge, of and in both areas.

Through our course we sought to offer the teacher-participants meaningful professional development that would have their personal and social transformation as its end result (Loucks-Horsley et al., 2003). By making critical literacy the focal point we could choose and assign texts about the HGP anticipating that teacher-participants would grapple with its implications at an elevated and transformative manner. We planned to have teacher-participants improve their critical literacy skills by discussing, actively reading on, critically writing about, and using evidence to support conclusions on issues arising from recent scientific discoveries. As one teacher-participant offered about her experience in learning to apply critical literacy, "I research, speak about, listen to, and understand the concepts that apply to writing about the various issues related to this topic" (A.T., emphasis ours). Although comments such as these indicate participants' active role in becoming increasingly critically literate, we plan to evaluate the degree of achievement in a future research project. The scope and duration of this project was such that we were unable to focus specifically on the depth of the transformative experiences, but instead chose to focus on the teacher-participants' improvement in their active reading and critical writing skills as it pertains to the HGP and the ethical, legal, and social implications of it.

\section{Scientific Thinking}

Our aim was to construct an interdisciplinary educational sequence as we highlighted the science of genomics throughout the course. Thus we searched for the values and methods that sustain the scientific enterprise to weave into the course on HGP and critical literacy. We identified characteristics of scientific thinking that were akin to those used by the critically literate, including the logic of scientific thinking and the skeptical attitude scientists use in their work. Logic allows one to make sound conclusions by relying on evidence, while skepticism asks one to resist accepting a belief without good reason as well as to be openminded enough to hold beliefs tentatively. Looking back to Freire we posited that his "pedagogy of hope" would build reasoning skills such as are exercised in logic and would denounce gullibility as an oppressive tactic (Freire, 1970). We believe that Freire would agree that critical literacy parallels scientific thinking in many ways. Furthermore, recent cognitive research from investigators such as Donovan and Bransford (2005) suggests that teaching science in more socially constructivist ways can be more effective than the use of transmission models, therefore teaching strategies using small group work and discussion were frequently used. Equipped with the goal of promoting critical literacy in a collaboratively taught, interdisciplinary course that explored the HGP and associated issues, we felt that we could adequately tap into the development of scientific thinking at the same time. (Readers wishing to access some of the activities and assignments that were designed to promote the goals described in this essay as well as some of the assessment tools and data resulting from the evaluation of this study may do so at http://hercules.gcsu.edu/ mgleason/ teacherquality/06supplementarydata.htm.)

\section{METHODOLOGY}

The participants in the course were in-service teacher-participants from schools in central Georgia counties. Eight of them took the course for graduate biology credit while the same number enrolled for English credit. The class was conducted for six hours daily for eight days over two weeks. The assigned texts, Genome by Matt Ridley (2000) and assorted readings from the ELSI Institute and other popular and academic texts were sent in advance so that teacherparticipants could prepare for the intense demands of the short course. Teacher-participants were assessed using two pre- and postinstruments, (an essay and a concept map), given before instruction and again on the last day to provide measures of learning gains. The essays were used to gauge teacher-participant awareness of the HGP, while the concept maps measured the complexity of teacher-participants' critical thinking skills that developed as they assimilated new knowledge. Three summative formal essays were used as a principle means of grading the teacher-participants in the course. Students were given rubrics to guide their writing of these essays. The first two of the essays have also been evaluated via a separate assessment rubric. Teacher-participants engaged in other formative and summative assessments such as "minute papers" about the direction of the course, peer editing and review sessions, classroom discussions received written feedback from instructors on essays on topics they selected and investigated, and made selfassessments of developing skills throughout the course (e.g., journaling). These assessment techniques allowed us to evaluate nuances of teacher-participant learning that the preand postassessments could not as readily address. Various assessment tools, rubrics, or schemes used to analyze the teacher-participant works can be found at the website noted above along with additional evaluative data and some materials from the course.

While the format of each day varied, nearly every day included an intensive scientific investigation and writing period. This entailed direct instruction from the professors (authors of this paper) and supplementary content support from two graduate assistants, one of whom had expertise in genetics and the other who was well-grounded in communication and critical literacy. It also included discussion in large and small groups, (often in relation to a case study), 
and questions from professors directed at scaffolding teacher-participants' connections among personal, professional, pedagogical, and scientific issues relating to the HGP. We designed this rich interplay of learner-centered activities based on the constructivist principles of Tharp and Gallimore (1989), along with our personal experience with such principles, with the intent that it would foster rapid assimilation of the HGP content and the critical literacy skills needed to address its issues. We also believed that these activities would become models that the teacher-participants would implement in their own classrooms so that the students they worked with might develop critical literacy skills as well. Participants received feedback on their written work; in addition, they completed peer and self-assessments to stimulate their thinking about any changes being wrought. From the learning activities mentioned above we selected a range of formats-written, visual, and oral discussion-as the basis for our interpretations.

Pre- and postessays (informal writings) were quantified by counting the number of times a teacher-participant wrote about a distinct HGP fact or issue. Factual errors were counted as well. A scholarly essay rubric was used to quantify the first two formal writings of the teacher-participants. Similar to the criteria included on the rubric they used to guide their writing, we applied two broad categories to assess their argumentation and substantiation skills by examining their "reflections on societal impacts" and their genetics comprehension by quantifying and scoring the quality of their distinct understandings of the "relationship between Mendelian and molecular genetics" and their use of "genetic nomenclature." Concept maps were scored by a scheme to quantify critical thinking. This scheme assigned points for the complexity of each of the ideas expressed (low: more concepts than interconnections identified within the concept map [1] or high: more interconnections than concepts identified within a concept map [2]) as well as the number of multiple connections, multiple levels, or additional self-selected concepts indicated on a concept map. While we created our own concept map scoring scheme, it is similar to those used by others in science education to find a general measure of the depth of cognitive change that might be occurring (Novak, 1991). The changes we expected in the informal writings and essays included the participants' use of stronger arguments based on evidence from concepts addressed in the course, more robust use of logic skills, and to a lesser degree, improvement in mechanics and usage. Regarding the concept maps, we expected teacher-partici- pants to identify a greater number of genomic concepts (nodes) and indicate more relationships between concepts (propositions) as a result of their learning. Additionally, we hoped to see teacher-participants increase the number of levels to include concepts, subconcepts, and details. All of these features would contribute to what we termed complexity. We used direct quotations from their written output as a part of the documentation of the qualitative outcomes.

\section{Findings}

The ultimate aim was for participants' to adopt a critical stance toward issues associated with the HGP and to extend this personally and professionally beyond the requirements of the course to assist in their intellectual development. The objectives included the acquisition of genetics content knowledge as well as skill in incorporating and then applying critical literacy strategies in science with middle and high school students. The participants were continually asked to examine the HGP for its consequent, and often, provocative issues throughout the course.

The data we address below include: 1) informal writing tasks which allowed us to document changes between the two pre- and postassessments (a writing assignment about HGP issues and a concept map on genetics knowledge), 2) formal essays written at the beginning and middle of the course, 3 ) the use of concept maps, which allowed the enumeration of issues-scientific, ethical, or social-identified by teacher-participants, 4) group discussions and critique of the film GATTACA (Nichol 1997), and 5) a final journal entry completed about the meaning and applicability of critical literacy. For this we directly quoted from the teacherparticipants' papers.

\section{Informal Writing}

The same written assessment was conducted before the first day and on the last day of the course to be used to identify any learning changes. In a 30-min time period and without the use of reference materials teacher-participants were asked to write what they knew about the "Human Genome Project and associated genetic issues." A simple quantification of distinct facts about the HGP, ELSI issues related to HGP, and incorrect statements is given in Table 1 for preand postassessments given for English teachers $(n=8)$ and biology teachers $(n=8)$. As expected, on the postassessment, all teacher-participants demonstrated dramatic gains in their awareness of the project's implications. More strik-

Table 1. Quantification of HGP facts, issues, and factual errors cited by English and science teacher-participants in their written preassessment and postassessment essays

\begin{tabular}{|c|c|c|c|c|c|c|}
\hline \multirow[b]{2}{*}{ Teacher-participants } & \multicolumn{2}{|c|}{ Facts } & \multicolumn{2}{|c|}{ Issues } & \multicolumn{2}{|c|}{ Errors } \\
\hline & Pre & Post & Pre & Post & Pre & Post \\
\hline English & $0.9 \pm 0.4$ & $5.1 \pm 0.5$ & $1.8 \pm 0.3$ & $5.2 \pm 0.9$ & $0.5 \pm 0.3$ & $0.25 \pm 0.2$ \\
\hline Science & $3.1 \pm 0.7$ & $4 \pm 0.6$ & $1.6 \pm 0.8$ & $5.5 \pm 0.8$ & $0.25 \pm 0.2$ & $0.25 \pm 0.2$ \\
\hline
\end{tabular}

Quantification of HGP facts, issues, and factual errors cited by English and science teacher-participants in their written preassessment and postassessment essays. Individual instances were scored twice by one reader and then averaged. Means of two cohorts are shown along with SE of mean. 
ing, though not unexpected, the eight English teacher-participants exhibited substantial gains in comparison to the eight biology teacher-participants, in their basic understanding of the science supporting the HGP.

Preassessment comments from English teacher-participants covered a considerable range. At the lower end, some teacher-participants professed essentially no knowledge to vague awareness such as: "[I have] little knowledge of the 'genome project and associated genetic issues' but I've read about a 'cloned sheep" ful to forensics workers" (D.W.). Another person felt that his knowledge about the "...HGP can fit inside a thimble" (B.G.). A third English teacher-participant wrote about Mendel and his "purple or white flowers, twirling or straight vines" (A.T.). Some English teacher-participants at the course's commencement described the science of the HGP using technical jargon, such as "genes consist of 23 pairs of chromosomes" (S.B.), or "isolating a part of a chromosome that is responsible for different things" (L.A.). By contrast, at the course's end, teacher-participants saw the HGP's science, albeit still imperfectly, with a more complete lens, that shed relevant light on their understanding of its implications: "The HGP is the effort by science to understand the story of each individual as revealed through his or her genes" (A.T., emphasis in original), "[N]ow that we have identified the components of the genome itself, what do we do with what is uncovered?" (S.B.), and ". . . ethical implications [of the HGP] involve determining what alleles are acceptable to select... and [the limits of] reproductive freedom/control" (L.A.). Finally, one English teacher-participant who came in with a "thimbleful" of knowledge saw himself at the end of the course as a "mason jar now overflowing" with knowledge about the HGP (B.G.).

The biology teachers, on the other hand, exhibited a basic awareness of the HGP. In their initial essays, all but one correctly including historical information such as, "The HGP began in 1990" (W.J.) or, "It is attempting to identify the sequence of every base [pair] of DNA in the human genome" (V.Y.). Again, this is not surprising, because presentation of the history of the HGP is a component of the state's life science curriculum. Nevertheless, gains in genetic knowledge were made, as their postessays showed a firmer grasp of the genetic processes and biological science addressed in the course. One example included a high-school biology teacher with an enhanced discernment of the connection between linkage groups and polygenic traits, as well as the ability to distinguish between different forms of neonatal genetic testing, such as preimplantation genetic diagnosis (PGD) and amniocentesis (CG).

\section{Formal Writing}

In addition to being provided with reading materials before the class began, teacher-participants were provided an essay rubric detailing the requirements to be met for each paper; from this rubric we created an essay scoring rubric aligned with those requirements. After intense discussion of the issues under consideration on the first and second days of class, teacher-participants were asked to research and write about "the right of the parent to choose a child's traits." Similarly, on the fourth and fifth days of class they were asked to write about "genetic discrimination." We codified the gains evidenced in these writings by assessing genetics / HGP knowledge and ability to research, explicate, and substantiate that knowledge. Instances of each of these rubricscored measures are presented as overall measures of "argumentation and substantiation" and a "combined genetics understanding and nomenclature use" for both papers and comparing the English teacher-participants to science teacher-participants (Figure 1). The data largely matched expectations: there were gains on the parts of both the English and the science teacher-participants in terms of knowledge of the HGP and associated terms and issues, although the gains were greater on the part of the English teacher-participants. Specifically, a better understanding of a basic relationship between molecular and Mendelian genetics was exhibited, as was an increased comfort with the nomenclature of genomics. This was shown in their writing by employing such terms as 10q26 (a locus region on a chromosome) and gene name symbols (e.g., LEPR or
Figure 1. Overall rubric scores for the first and second essays are presented for the English teacher-participants (striped bars) and the science teacher-participants (solid bars). Error bars show SE of the mean.

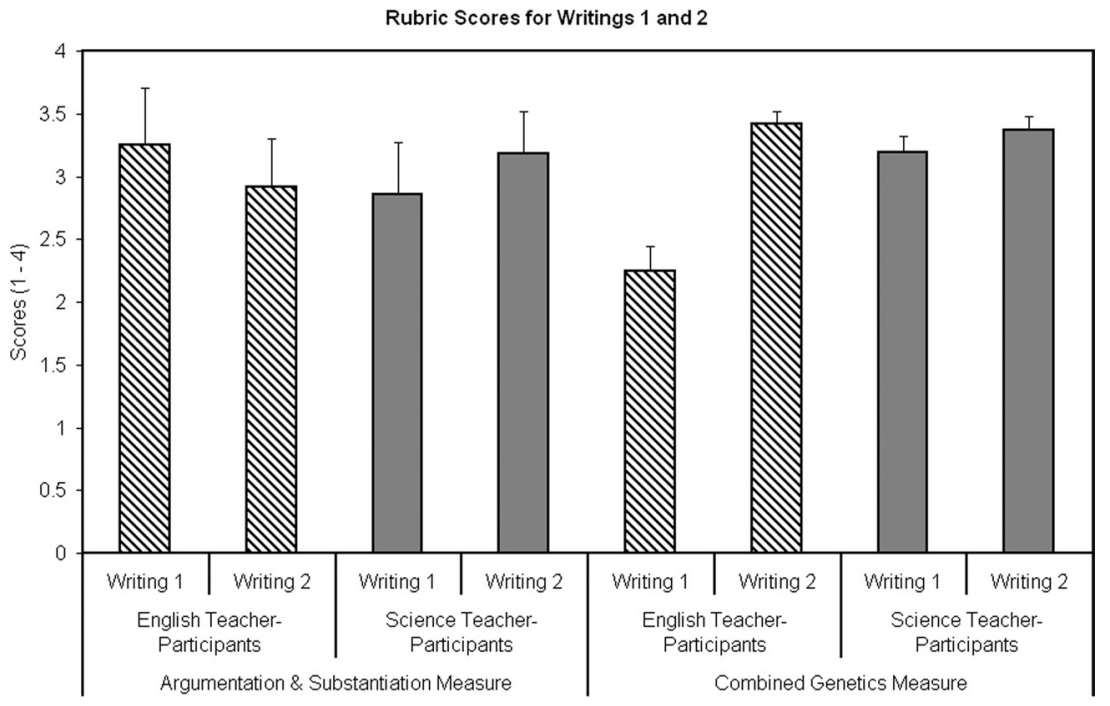




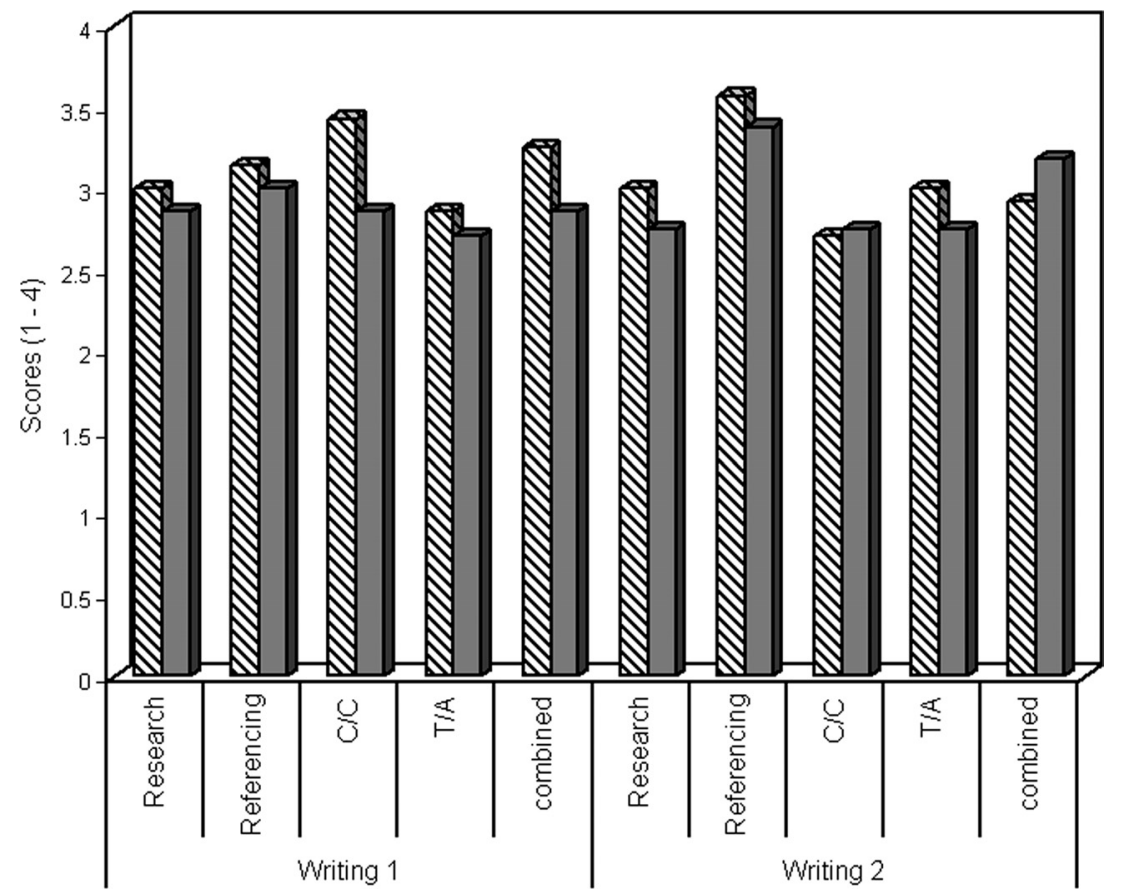

Figure 2. Essay 1 and 2 rubric-subscores for argumentation and substantiation skill measure are presented for the English teacher-participants (striped bars) and the science teacher-participants (solid bars).
ENGRAILED). One unexpected result, however, was the slight decrease in English teacher-participants' facility in creating meaningful propositions (completeness and coherence) to support their arguments on the second paper, as is shown in Figure 2. These findings were obtained from examination of the subscores for "argumentation and substantiation." Our explanation for this is that, although their writing skills were polished insofar as discussing literature and doing literary analysis, there was some cognitive dissonance created when they were confronted by completely new terms and ideas. Recent publications in a special Science issue dedicated to the language, literacy, and science (American Association for the Advancement of Science, 2010) suggest this proposition is one that we could explore in future research. Even with this slight discrepancy on the part of the English participants, however, it was apparent that the quantity and quality of each teacher-participant's written assessment tasks became richer and more detailed; overall, they demonstrated a critical, thoughtful approach to the issues raised in class. Additionally, most of the overall science teacher-participants improvements in "argumentation and substantiation" seemed attributable to gains in their documentation skills. A table presenting the rubric scores used in this analysis is found on the accompanying website (see http://hercules.gcsu.edu/ mgleason/teacherquality/ 06supplementarydata.htm).

\section{Concept Maps}

In general we anticipated that the biology teachers would have more content knowledge about genomics before instruction while the English teachers would have better writing skills. Although this supposition generally held it was not true in all cases, as three teachers registered in the biology section taught Earth or physical science and had less knowledge of genomics than did the other science teachers in the course. The participants were not told the main concept around which to arrange their maps but were asked to include 12 prescribed terms when constructing the map. However, they were encouraged to include additional ones if they could.

Six of the eight science teachers organized all 12 terms correctly if superficially on the initial concept map. One was incomplete, using only three terms, and one was organized in no coherent manner and not documented on the accompanying website. The biology participants selected terms that suggested a more global approach to the task such as inheritance or genetics, or tended to apply one of their own as the organizing concept for the map, whereas the English teachers frequently used the term (one that they may have heard in popular media) DNA, as the organizing concept. Two high school teachers added many more terms than the 12 provided and one middle school science teacher was the most elaborate in establishing relationships between concepts, also called propositions, on her map. Although instructed to do otherwise, five of the eight science teachers provided few $(<3)$ to no propositions on their concept maps in advance of the course. Example of English and science teacher-participants pre- and post-concept maps are shown in Figure 3. All concept maps and their individual scores can be seen at the accompanying website (http:/ / hercules.gcsu.edu/ $\sim$ mgleason/teacherquality/06supplementarydata.htm).

The maps constructed by the English teachers' for the most part revealed little initial knowledge of genetics. As a whole their understanding was below the basic level. Only one person included propositions, one added many additional terms but they were ethical rather than life science concepts, and only two selected truly central terms such as inheritance around 

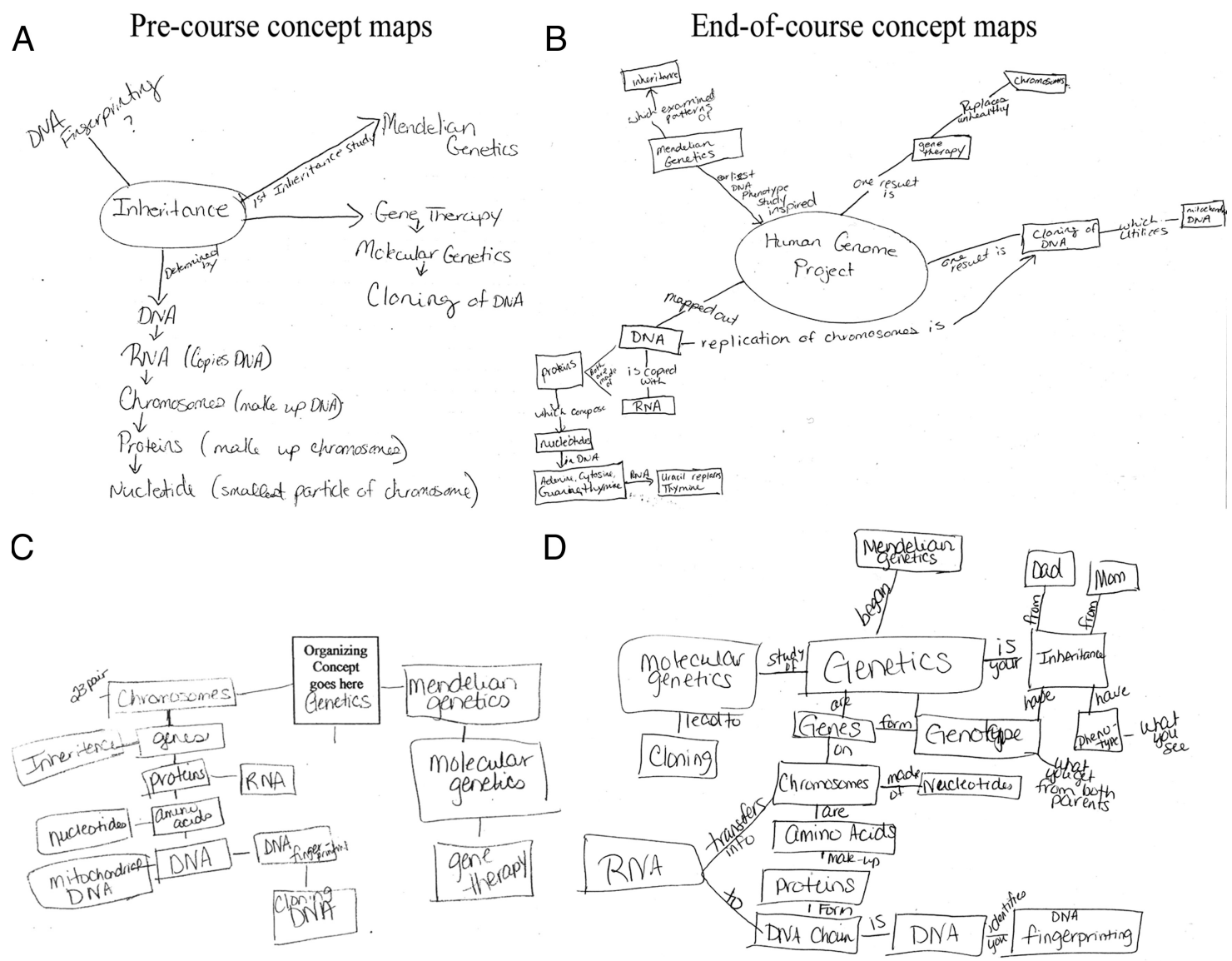

Figure 3. (A and B) Pre- and postconcepts maps for an English teacher participant that improved in complexity score from a 2 to a 5 . (C and D) Science teacher-participant that improved from 2 to 4 .

which to organize the map. Two were so minimal as to not be open to our analysis of their conceptions.

The concept maps completed as a postassessment instrument were noticeably better developed, in terms of complexity for essentially every teacher-participant. Granted, the teacher-participants had a small amount of instruction on how to use concept maps as assessment tools that may have led to their improved construction. However, the instruction provided little more information than they were given in the original instructions such as to be explicitly told to include propositions to indicate relationships between concepts. An example of a postassessment concept map drawn by one of the English teacher-participants is shown in Figure 1, and the scored results are available on the website. Every class member arranged all 12 terms, including mitochondrial DNA, in a logical manner, and all but two provided propositions that established accurate relationships between concepts. Ten teachers-participants, six science and four English, used sophisticated propositions (three or more words in the phrase used to create more than a simple predicate) to denote the relationships among concepts with six actually showing two or more relationships with a single concept demonstrating increased complexity. Fifty percent of the participants included more subconcepts on the postassessment than required, and many were creative in their choice of the organizing concept. Two English teacher-participants organized around the term HGP, one around genetic discrimination, and one around cells, suggesting overall heightened, more global insights, and a much richer conception than they demonstrated originally. The map of one person, initially at the lowest level of conceptual understanding, remained so, but generally we think the concept maps revealed that the learners developed a much more solid knowledge base with a more advanced facility to consider the concepts at a high level or with more complexity.

\section{Group Discussion and Film Critique}

Discussion was a frequent strategy throughout the course, at times facilitated by the professors with particular questions used as prompts. While the data described in this section are anecdotal, we noticed several interesting patterns that indicated our teacher-participants were indeed learning more about issues related to the HGP. In comparing participants' oral responses to directed-questioning during early and late discussions in the course, we found that almost all the science teachers showed detailed understanding of reproductive, biological, and genetic technologies, by the end of the course. Similarly, more-detailed responses were also exhibited by at least half of the English teachers by the end 
of the course, though their robust understanding of each technology was more limited than the life science teachers' responses. One example of the subtleties in discernment that the teachers' displayed included the ability to discriminate neonatal genetic testing technologies, such as PGD and single nucleotide polymorphism (SNP) analysis, from assistedreproduction technologies such as hyperovulation and in vitro fertilization. Going from that seemingly 'simple' analysis earlier in the course to a more sophisticated ability later on, in which teacher-participants distinguished these two categories from biological discoveries in the fields of cloning and embryonic stem cell studies, we felt, was a triumph for all concerned.

Similarly, we saw interesting responses when participants critiqued the science fiction film GATTACA both at the beginning of the course and after eight days of instruction. We asked them to list incidences they saw that they would identify as science and biotechnology, as well as issues they would place in the legal, social, or ethical implications category. We noticed that teacher-participants were able to identify more such issues upon the second viewing, which we believe reflected the depth to which they came to understand both scientific concepts as well as ELSI issues. As one teacher-participant wrote, "It was also much more poignant because I realize how truly close it is to reality and not fantasy" (A.J., emphasis in the original).

\section{Quotations from the Final Journal Entry}

In the final writing assignment participants were asked to define critical literacy, how they had been using it in the course, and how they might use the HGP and the issues it evokes to promote critical literacy. As one biology teacher wrote, "[C]ritical literacy means reading," but then elaborated that it involves multiple processes (reading, viewing, discussing, documentation, and writing) with critical questioning, "[I]s the author knowledgeable on this subject? Do they know enough to write about it? ... present a good case for their point of view? Are you convinced by their documentation that they are correct in their stand and if not, why not?" He then went on to write ". . . after this [critical analysis] the person can now formulate their own position ... based on clear evaluation of material and not just emotions" (J.D.). Another added that critical literacy takes students to the next level of library research, because too often they "... are not made aware that they can question sources" (S.B.). As regards use of critical literacy during the course, P.C. typified many when she wrote, "I am applying critical literacy by reflecting on issues concerning all of us. By examining issues that affect us, I now ask myself, how does the knowledge promote the health and well being of individuals in a society?" With reference to the use of HGP as a pretext for teaching critical literacy, J.P., an English high school teacher, wrote, "I would definitely use GATTACA as ... a launch-pad for discussion of both 'literary' elements like symbolism [and] more scientific themes [like] what a gene is, what its function is, how does the HGP, gene therapy, and genetic selection have political, social, and cultural impacts..." In addition, he added, "I would use external reading material ... like Ridley's Genome... and then have them write about their impressions." Some of the teacherparticipants were in agreement that the subject matter we used was effective in promoting critical literacy. Others indicated that more succinct accounts, such as newspaper articles that we introduced from daily newspapers published during the course, would be more accessible to their students and add the relevancy of 'current events' (J.D.). Finally, several participants felt as one learner did, that the course made her, "feel more secure in discussing this material with my students" (VY). Participant reflections reveal an understanding of how critical literacy can be used effectively in multidisciplinary courses.

\section{Final Lessons Learned}

We felt the course was successful in many ways because the participants appeared to advance a great deal in a short period of time. We attributed the participants' enhanced professional and intellectual development to the personalized focus on thoughtful reading and writing they encountered with us throughout the course. We intend to follow up with more study to determine if indeed, teacher-participants improve in their ability to share their knowledge of the HGP with future generations and anecdotal data have been encouraging but this will take more resources than we have available at this time. Additionally, we anticipate that the modeling, instruction, and expectation for implementation provided through the community of discourse will strengthen the teachers' ability to bring all of their students to high levels of achievement. Many of the teacher-participants felt that meaningful activities they had utilized to explore social, ethical, and legal implications of the HGP, would increase their ability to elicit the enthusiasm of their students for biology and literature. For example, the biology teachers benefited from discussions, reading, and writing exercises that opened their minds to the implication of the HGP and spoke earnestly of trying to find ways to incorporate such activities into their classrooms. While the English teachers benefited from these activities as well, it was in the context of controversy that the science that they learned took on an even greater importance. All of the English teachers felt they would now be comfortable working with students writing essays like they wrote in class and some looked forward to tackling literature dealing with such subjects in their classroom as result of this course. We are hopeful that the teacher-participants have taken with them a more critical stance on all areas of science and life and will guide their students to do so as well.

In many of our courses we do not always feel we have the liberty or time to teach in this more responsive style. In this situation, however, we found the experience freeing as colleagues and teacher-participants from quite diverse fields, and our interactions increased our personal and professional growth. One measure of this was the degree of responsiveness and flexibility that we developed on a daily basis as this course evolved. Another was the many insights into literacy improvements we have described. In toto, we believe these factors have been and will be put in place in all of our future courses, and in many of the classrooms of the teachers who took this class.

This innovative course challenged us, the instructors, to communicate in many areas, such as integrating our teaching methods, materials, and ways of assessment. Although we met for many planning sessions before the course, we found that we had had to frequently assess and respond to 
a changing learning environment. We consulted with each other and with the graduate assistants throughout the day and more extensively almost each afternoon in debriefing sessions. Besides discussing technical and logistical considerations, we had to learn how each of us addressed issues associated with the topics that had arisen in class about the HGP and what we believed our teacher-participants were gaining from the course. Hence, we recommend that as other instructors design and implement interdisciplinary courses that they make it part of their plan to set aside time to communicate during the course as well. As a learning experience we calculate this to have been beneficial for all involved and expect it to be similarly successful for the learning of middle and high school students.

\section{ACKNOWLEDGMENTS}

The authors thank the dedicated service of Spencer Pucci and Jennifer Lindenberger, whose assistance helped the course run smoothly. Funding for the course described in this paper was provided by a "No Child Left Behind" Title II Part A Higher Education Improving Teacher Quality Higher Education Grant from the U.S. Department of Education (2006-1SLRB3) and the GCSU Science Education Center. Courses previously taught by Drs. Gleason and Kleine were also funded the U.S. Department of Education under the auspices of Eisenhower Higher Education Grant Program (2002-03SD2) and the Improving Teacher Quality Grant Program (2003-1SD6).

\section{REFERENCES}

Alvermann, D. E., and Hagood, M. C. (2000). Critical media literacy: research, theory, and practice in "New Times." J. Educ. Res. 93, 193-205.
American Association for the Advancement of Science (2010). Science 328.

Donovan, S. M., and Bransford, J. D. (2005). How Students Learn: History, Mathematics, and Science in the Classroom, ed. Susan M. Donovan. Washington, DC: The National Academies Press.

Freeman, G., and Taylor, V. (2006). Integrating Science and Literacy Instruction: A Framework for Bridging the Gap. New York: Rowman and Littlefield Education.

Freire, P. (1970). The adult literacy process as cultural action for freedom. Harvard Educ. Rev. 40, 205-212.

Gleason, M. L., and Kleine, K.L.M. (2003). Teaching GATTACA, Poster 1384 presented at the $43^{\text {rd }}$ Annual Meeting of American Society for Cell Biology, San Francisco, CA (ASCB), 106.

Loucks-Horsley, S., Love, N., Stiles, K. E., Mundry, S. E., and Hewson, P. W. (2003). Designing Professional Development for Teachers of Science and Mathematics, $2^{\text {nd }}$ ed. Thousand Oaks, CA: Corwin Press.

National Research Council (1995). National Science Education Standards: Observe, Interact, Change, Learn. Washington, DC: National Academies Press.

Nichol, A. (writer and director of GATTACA DVD) (1997). United States: Columbia Tristar Home Entertainment, 2002.

Novak, J. (1991). Concept-mapping: a useful tool for science education [Electronic version]. J. Res. Sci. Teach. 36, 475-492.

Ridley, M. (2000). Genome: An Autobiography in of a Species in 23 Chapters. New York: HarperCollins Publishers.

Simpson, A. (1996). Critical questions: whose questions? The Reading Teacher 50, 118-127.

Taylor, P. V. (1993). The Texts of Paulo Freire. Buckingham, UK: Open University Press.

Tharp, R. G., and Gallimore, R. G. (1989). Rousing Minds to Life: Teaching, Learning, and Schooling in Social Context. New York: Cambridge University Press.

Wink, J. (2004). Critical Pedagogy: Notes from the Real World, $3^{\text {rd }}$ ed. New York: Allyn and Bacon. 